\title{
A (FORENSIC) STYLISTIC ANALYSIS OF ADVERBIALS OF ATTITUDE AND EMPHASIS IN SUPREME COURT DECISIONS IN PHILIPPINE ENGLISH
}

\author{
Hjalmar Punla Hernandez \\ University of the Philippines Los Baños, Philippines \\ hernandezhjalmar070@gmail.com; hphernandezl@up.edu.ph
}

First received: 19 June 2017

Final proof received: 26 September 2017

\begin{abstract}
Contemporarily, stylistics today has developed into its multiplicity - one of which is forensic stylistics. Being a powerfully legal written discourse, Supreme Court decisions are a rich corpus in which linguistic vis-a-vis stylistic choices of Court justices could be examined. This study is a humble attempt at stylistically analyzing Supreme Court decisions in Philippine English (PhE) drafted by two Filipino justices. Specifically, it sought to investigate on the classes, placements, and environments of adverbials of attitude and emphasis employed by the two justices, and drew their implications to teaching and learning English for Legal Purposes (ELP). Using McMenamin (2012), Quirk, Greenbaum, Leech, and Svartvik (1985), and Dita's (2011) frameworks, 54 randomly selected Supreme Court decisions as primary sources of legal language were analyzed. Results are the following. Firstly, the classes of adverbials of attitude in Supreme Court decisions in PhE used by the two judges were the evaluation to the subject of the clause, judgment to the whole clause, and evaluation to an action performed by the subject of the clause, while those adverbials of emphasis were adverbials of conviction and doubt. Secondly, both adverbials they used have placements that were frequently medial and less initial in sentences where they belonged. Thirdly, the two justices put their adverbials within two principal environments, i.e. within functor, and before/after the verb among others. In these regards, legal and stylistic explanations with respect to these recurrent linguistic features in the two justices' Court decisions were revealed. Implications of the study to ELP are explained. Lastly, trajectories for future (forensic) stylistic analyses have been recommended.
\end{abstract}

Keywords: stylistics; forensic stylistics; adverbial expressions of attitude and emphasis; Supreme Court decisions; Philippine English

In the $21^{\text {st }}$ century, stylistics as the study of style in language (McMenamin, 2012) has gone far beyond being conventional. Applied linguists observe and analyze the chronically idiosyncratic representation of authors (or speakers) particularly by looking into the style markers they use in order to determine the linguistic regularities portrayed by them. In turn, this can be described as peculiar, and thus be used to detect the writing style of an individual. Stylistics traditionally lays its emphasis on the stringent adherence to language to syntactic accuracy and social correctness in terms of literary stylistics, which has placed itself to contemporary stylistics such as forensic stylistics, an area of innovative linguistic exploration at present.

Forensic stylistics, a sub-branch of forensic linguistics, is the analysis of linguistic differences of written language in dispute (McMenamin, 2012). As its focus is on the consistent and varying use of language, the concentration of a legal document under investigation is on handwriting, computer-generated documents, inks, to name a few. While forensic stylistics is something new as far as stylistics is concerned, it is yet a fertile ground of linguistic analysis, as forensic linguistics is an emergent field of linguistic studies in the Philippines. Concurrently, analyzing forensic or legal texts is actually receiving a growing interest or popularity (Cruz \& Pariña, 2015) among linguists. In addition, studies on the authorship of legal English discourse are an aspect which applied linguists, if not often, seldom put their attention to.

Having exposed the aforementioned, this paper addresses these gaps by investigating a linguistic facet of legal English discourse, i.e. adverbials, found in the Supreme Court decisions in Philippine English (henceforth $\mathrm{PhE}$ ) drafted by two Supreme Court justices in the Philippines. Vitally, Finegan (2012) asserts that adverbials are not given much-paid consideration as far as legal language is concerned. Judges' dispositions furthermore manifest in the writing style they lay against Supreme Court decisions (Ambwani, 2015) despite the detachment expected of them. Likewise, this study humbly attempts at analyzing the stylistics of adverbial expressions of 
attitude and emphasis in Supreme Court decisions in $\mathrm{PhE}$ and implicating its findings towards the pedagogy of English for Legal Purposes (ELP).

This paper begins with a discussion of legal discourse, Supreme Court decisions, and Philippine English. It then elucidates on adverbials of attitude and emphasis and their syntactic features and synthesizes stylistic analyses of legal documents. Subsequent are the research questions, method, findings and discussion, and conclusion. Apart from the study's implications to ELP, it also emphasizes potential directions for future (forensic) stylistics studies.

\section{Legal discourse, Supreme Court decisions, and} Philippine English

Legal discourse like academic discourse is either spoken or written. Particularly, written legal discourse has three primary genres (Krivchikova, Koteneva, Sedykh, \& Trescheva, 2015): (1) the laws (e.g. Constitution, foundations, codes), (2) sub-legislative statements (e.g. decisions, decrees, instructions, and so on), and (3) scientific special legal literature (e.g. monographs, textbooks, legal periodicals, and so on). It is characterized by its peculiar lexical, syntactic, and graphological features (Alabi, 2011). Filled with foreign terminologies, the legal written discourse is wide-ranging in terms of its lexemes. Latin and French loan words such as obiter, habeas corpus, ratio decidendi, and commission rogatoire are abundant. Similarly, it contains abbreviations like $V$. for versus, C.A. for Court of Appeal, Div. Ct. for Division Court, and contra for an authority opposing what a person has stated. Syntactically, another nuance of such discourse is its word-forming peculiarity as the use of suffixes -or and -ee, for example, mortgagor, and mortgagee. Stringing adverbs and prepositions to form new words is also common such as there and to (thereto), here and by (hereby), and where and of (whereof) to name a few. Moreover, using modals like will (as a marker of futurity) and shall (as a marker of futurity and imperativeness) is frequent. It is the inversion of word order that is striking in legal texts. The juxtaposition of words like night and day, childbirth and pregnancy, and death or bodily injury would typically appear as day and night, pregnancy and childbirth, and bodily injury and death reversely. That arrangement hints the important points to be emphasized so a client would not fail to catch the point being conveyed in the legal text. Long sentences are usually used in proceedings, reports, oaths, and judgments (Alabi, 2011). Graphologically, gothic writing style is employed also. Bold characters are used to capture exceptional attention and introduce main paragraphs. Complex sentences typically are setoff by either commas, semi-colons, or entirely broken, or no punctuation are employed except periods (Alabi, 2011). Supreme Court decisions are just one of the legal texts that possess these distinctions.

Being a sub-legislative legal discourse, Supreme Court decisions on the grounds of order are the final product of court proceedings. While its style differs from one judge to another, it reflects the disposition of a judge as he has his own way of writing (Ambwani, 2015). Though it uses legal language, it should be understood by individuals who lost in the case. In civil law, according to Ambwani (2015), decisions may be long or short. Long and justified decisions are required in original suits such as permanent injunctions, contract performance, and document cancellations to name a few. Short decisions are drafted in matters like review, preliminary issues, summary suits, and so on. Legally, the Code of Civil Procedure, 1908 and Code of Criminal Procedure, 1973 elucidate the tenets for writing judgments. However, Ambwani (2015) argues that decisions still have the judge's preference to choose his language and writing style. A judgment is a work of a judge who acts his reasoning and provides truthful opinions that the appellate Court should discern no error or misleading supposition. It also reflects the integrity, fairness, worthiness, and intellectual honesty of a judge as an active member of morally legal tradition. Legally, a decision should start with accurate presentation of facts, root of case, and the fashion in which the case reached the Court. While all of these should be drawn from the accounts of Court proceedings, only relevant pieces of evidence and/or narratives must be expressed precisely and clearly. Before inscribing the findings on the judgment, all relevant pieces of evidence must be deliberated by the judges. There are no definite rules as to how a finding may be recorded, but the judge should support his findings with reasons. This time, he has to be guided by the standards of drafting judgments since he may also possess preferences, predispositions, partiality, and subjectivity (Ambwani, 2015) until he arrives at a conclusion. The judgment can be drafted plainly and simply. Plain and simple English language involves linguistic features not limited to reasonably average sentence length, short words, no double negatives, active voice, parallel structure, no excessive references and mazes, and legalism overuse. All of this adds quality to the judgment, and whatever legal language (orthodox or plain) through which it is expressed speaks the character of a judge (Ambwani, 2015). Generally, however, the English language is the language of law. Since English varies in one language domain to another as it differs from one sociolinguistic context to another, the English used in drafting Court decisions in the United States is definitely not the English that is used in writing Court decisions in the Philippines. 
Thus, Philippine English is the variety of English that Filipino judges use in expressing their decisions in Supreme Court judgments.

While trailblazing syntactic studies of $\mathrm{PhE}$ were innovated by Llamzon (1969), corpus-based studies of $\mathrm{PhE}$ using the International Corpus of English Philippines (ICE-PHI) can be officially traced in Bautista's monograph, Defining Standard Philippine English: Its Status and Grammatical Structure which describes subject-verb concord, tense and aspect, articles, prepositions in PhE (Bautista, 2000). Since then, various local and foreign linguists succeeded and explored the syntactic aspect of $\mathrm{PhE}$. Albeit copious studies on $\mathrm{PhE}$ were based on the ICE-PHI, profuse analyses of $\mathrm{PhE}$ utilized other corpora such as academic essays (Yumul-Florendo, 2012), newspapers (Hernandez, 2017; Gustilo, 2011), college textbooks (Bernardo, 2013), research articles (Gustilo, 2010), and lesson plans (Peña, 1997) had been undertaken. Any written discourse drafted by educated Filipinos is corpora of $\mathrm{PhE}$ that could be used as data for linguistic analyses. According to Martin (2014), educated Filipinos are those who have finished their formal education, for example, bachelor, master, and doctoral degrees. Hence, legal texts such as Supreme Court decisions written by Filipino judges and fiscals, which are learned, are actually $\mathrm{PhE}$ corpora. The link between Supreme Court decisions and $\mathrm{PhE}$ raises an impetus for stylistic analyses focusing on adverbials of attitude and emphasis.

\section{Adverbials of attitude and emphasis, as well as their syntactic features}

Finegan (2012) argues that adverbials are interesting foci of inquiry on a number of grounds. As they modify three content words, i.e. verbs, adjectives, adverbs, and entire clauses, thus, they show notable syntactic flexibility. Moreover, they signify attitude or stance, and emphasis. Adverbial markers that signify attitudes are, appropriately, correctly, fortunately, unfortunately, surprisingly, remarkably, inexplicably, importantly, significantly, happily, properly, and unfortunately (Finegan, 2012). For example (Finegan, 2012, p. 72),

\section{Not surprisingly, the parties vigorously disputed the waiver issue, and it sharply divided the Court. \\ The Court inexplicably concludes, however, that the liquefied natural gas (LNG) unloading wharf at stake in this litigation "goes well beyond the ordinary or usual.}

Quirk et al., (1985) treat adverbs of attitude as disjuncts that express value judgments (Dita, 2011). Specifically, "they convey some evaluation towards what is said" (Quirk et al., 1985, p. 621), and are grouped into two: the first is the adverbs of attitude that express an evaluation on what is stated as a whole in chorus to the subject of the clause. This occurs with judgments either passed on what is stated as true or false or on the wisdom of what is described. The former type can be correctly, incorrectly, justly, unjustly, rightly, and wrongly, while the latter can be cleverly, cunningly, prudently, reasonably, sensibly, reasonably, wisely, unwisely (Quirk et al., 1985).

The second is the adverbs of attitude that express judgment carrying the absence of implication to the subject of the sentence or clause. Quirk et al., (1985, pp. 621-622) illustrate,

Remarkably, Mrs. Jensen consulted her lawyer. [Her action was remarkable; the speaker is not suggesting that Mrs. Jensen was remarkable]

Besides the foregoing, adverbs that take no implication to their subjects can (a) judge what is said to be strange or unexpected (e.g. amazingly, curiously, incredibly, oddly, remarkably, strangely, suspiciously), (b) judge what is said to be expected (e.g. appropriately, inevitably, naturally, predictably, understandably), (c) judge what is to cause satisfaction or the reverse (e.g. annoyingly, delightfully, disappointingly, disturbingly, pleasingly, regrettably), and (d) judge what is said to be fortunate or unfortunate (e.g. fortunately, unfortunately, happily, unhappily, luckily, unluckily, sadly, tragically) (Quirk et al., 1985, p. 622).

Adverbials of attitude are not as much as adverbials of emphasis (Finegan, 2012) in legal texts. What are more abundant are adverbials of emphasis or emphatic adverbs that add prominence to the content but not alter it or do not modify content itself. Simply, indeed, merely, clearly, plainly, precisely, surely, readily, of course, particularly, actually, in fact, certainly, full, especially, highly are examples (Finegan, 2012). For instance, Finegan (2012, p. 73) cites,

But when discussing these words, the Court simply ignores the preamble. (But when discussing these words, the Court ignores the preamble.)

It is particularly appropriate for us to refrain from employing equal protection doctrine to thwart the will of the voters in this case.

Speaking of content, Quirk et al., (1985) call adverbs of emphasis as content disjuncts that can emphasize a degree of truth. The degree of truth content disjuncts provides a remark on the truth value of what is stated; expressing the extent to which the author asserts that what he is saying is a fact. They can either express (a) conviction or (b) doubt. Several adverbs of convictions are assuredly, certainly, 
definitely, indisputably, surely, unarguably, undoubtedly, patently, unquestionably, clearly, evidently, and manifestly, while adverbs of doubt are allegedly, apparently, conceivably, most likely, perhaps, possibly, presumably, purportedly, reportedly, reputedly, seemingly, and supposedly.

While these disjuncts are placed anywhere in a sentence, Dita (2011) explains that their common positions in clauses are initial (I), medial (M), and final (F). Common in written discourse, they are set off by commas from the clauses they belong; hence, they are detached. Dita (2011, p. 40) cites examples taken from the ICE-PHI.

Apparently, someone in his senior moment forgot to give you the corrected direction...<W1B-014\#108> (Initial)

Pizza, apparently, has already found her true... $<$ W1B-006\#101> (Medial)

Well it's been it's been functioning as a hotel also uh apparently $<S 1 B-038 \# 60>$ (Final)

In addition, they appear in split infinitives, other functors, before conjunctions, or within a noun phrase (Dita, 2011). Dita illustrates them as follows (Dita, 2011, pp. 40-41).

Uhm the only way to detect dengue is to basically have a uh blood test done <S1B-045\#54> (In Split Infinitive)

With only P13.3 billion worth of real estate in its books, there obviously won't be enough... $<W 2 C$ 009\#76> (Functor)

There will be nobody else fortunately or unfortunately like you. $\langle S 2 A-050 \# 43\rangle$ (Before Conjunction)

...some time in the seventies have now accepted that women are part definitely of the halftime palabas and I think ... $<S 2 A-007 \# 61>$ (Within a Noun Phrase)

\section{Stylistic analyses of legal documents}

Albeit Finegan (2012), Quirk et al. (1985), and Dita (2011) give detailed and clear explications about adverbials of attitude and emphasis, it seems that there has been uncharted stylistic analysis as regards these adverbials in Supreme Court decisions in PhE. This is actually suggested by the following studies driven by the macro levels of language: graphology, syntax, and lexicon (Simpson, 2004). By far, the current stylistic analyses of legal texts report about graphological, lexical, and syntactic features of legal discourse, while others focus on their microfeatures. On the macro level, Krivchikova et al. (2015) investigated the stylistics of legislative texts, i.e. grouped into three main genres: the laws, sub-legislative statements, and scientific special legal literature, which belong to the official-business-style. Similar to other styles of written discourse, legislative texts are characterized by narrow scope, standardization, expression and imagery, brevity and compactness, connectedness and continuity, impersonality and objectivity. However, they differ in terms of syntax, archaism, and conservatism.

Relatively, Feng (2012) discussed the stylistic features of legal English graphologically, lexically, and syntactically. Graphologically, legal English uses common capitalization, font style, and font size. Lexically, it is nuanced by archaisms, loan words from Latin and French, and technical words. Syntactically, it utilizes statements and complex sentences. These topographies of legal English also manifest in the study of Zhu and $\mathrm{Wu}$ (2011) who examined the stylistic features of English for business contracts from both a lexical and syntactic stance. The lexicon of business contracts is characterized as formal, archaic, loan, technical, and synonymous, while their syntax shows distinctiveness in terms of long sentences, and passive voice. Particularly, Khan, and Khan (2015), and Nawaz, Bilal, Khan, and Ahmed (2013) determined the stylistic markers and (their communicative functions and styles) of a Supreme Court judgment. Through graphological, lexical, and syntactic analyses, Nawaz et al. arrived at a description of the stylistics of the legal text. At grapheme level, the judgment uses lay-out italicization, and bold text, capitalization, missing lines, and dots, punctuation, brackets, and abbreviations. Lexically, the text uses archaism, jargons, enumeration, and any. Syntactically, the data were discovered to have nominalizations, unique determiners, impersonality, lengthy and complex sentences, conditional sentences, prepositional phrases, passives, pre-and post-modifications, negatives, and deviation from the norm of legal language.

On the micro level, Lisina (2013) contrasted English and Norwegian stylistic features atypical to legal written discourse. Complex prepositions and verbs pairs were discovered as peculiar to both languages. While complex prepositions appear in both, they are more frequent in Norwegian texts. However, English legal texts use complex prepositions more consistently. Regarding verb pairs, English verbs have neutral connotations but are formal in the Norwegian counterpart. Furthermore, Cruz and Pariña (2015) focused on the subordinate clauses in Court resolutions drafted by two Supreme Court justices to determine whether the clause structures used by the two conform to the nature of legal written discourse. Using Quirk, Greenbaum, Leech, and Svartvik's (1985) types of subordinate clauses for analysis, they found that the resolutions adhere to legal drafters' conventions of writing legal documents, that is, using nominal and relative clauses; thus, objective and detached. 


\section{Research questions}

In synthesis, the studies above imply no (forensic) stylistic analysis of adverbial expressions of attitude and emphasis in Supreme Court decisions in PhE has been made in the Philippine context. Linguists of legal discourse infrequently treat adverbials in depth (Finegan, 2012). More importantly, none of the above described the individual authorship of the legal drafters portrayed in the corpus they had written. Of the studies explored neither the adverbials of attitude and emphasis as stylistic markers or evidence of the customary and unconscious selections, which an author makes in his writing (McMenamin, 2012). The potential of Supreme Court decisions in PhE for (forensic) stylistic analysis cannot be devalued. Hence, this study sheds light on the following questions:

1. What are the classes of adverbials of attitude and emphasis in Supreme Court decisions in $\mathrm{PhE}$ ?

2. What are the placements of adverbials of attitude and emphasis in Supreme Court decisions in PhE?

3. What environments do adverbials of attitude and emphasis in Supreme Court decisions in $\mathrm{PhE}$ appear?

\section{METHOD}

The research used descriptive qualitative and quantitative research designs. The frequencies of the two adverbials are presented, while they are supported by sentential extracts drawn from the linguistic data.

Fifty-four (54) authentic Supreme Court decisions in $\mathrm{PhE}$ on civil cases drafted by two Filipino Supreme Court Chief Justices, (1) Reynato Puno (RP), and (2) Renato Corona (RC) were purposively selected. They were posted on December 08, 2007, to May 17, 2010, during the term of RP, and on May 17, 2010, to May 29, 2012, during the term of RC. Other Supreme Court decisions were not selected since they had been drafted by Associate Justices. In terms of the number of overall tokens, each corpus contains more than 1000 to 5000 words. In sum, the data comprised of 160.087 words.

All the Supreme Court decisions in $\mathrm{PhE}$ are actually downloadable online at http://sc.judiciary.gov.ph/. As they are virtually accessible, the researcher copied and pasted each of them from the web page to Text Document (.txt) since this is the only format that AntConc and UAM Corpus Tool (see Data analysis below for description) accept for corpus analysis. Though WordCounter is more flexible as it accepts a variety of text formats such as Text Document, Microsoft Word, PowerPoint, Excel, and Portable Document Format (PDF), the .txt format was also used for the purpose of efficiency. Each text was documented through assigning a specific file name, that is, LAST NAME OF CHIEF JUSTICEMONTH-DAY-YEAR (e.g. PUNO-02-15-2008). For decisions that have identical dates, a small case letter is assigned by the end of the file name as in a, b, or c (e.g. PUNO-08-12-2008b). This was done until all the texts were completely collected.

A top-down approach, the framework used in analyzing Supreme Court decisions is the one provided by Finegan (2012), Quirk et al. (1985), and Dita (2011). Their descriptions regarding adverbials of attitude and emphasis were utilized as the basis for the investigation of the said stylistic markers. There are four categories with sub-categories of adverbials scrutinized in the study: (1) adverbials of attitude, i.e. (a) evaluation to the subject of the clause, and (b) judgment to the whole clause; (2) adverbials of emphasis, i.e. (a) conviction, and (b) doubt; (3) placements of adverbials, i.e. (a) initial, (b) medial, and (c) final; and environment in sentences, i.e. $(a)$ in split infinitive, (b) with functor, (c) before conjunction, and (d) within a noun phrase. These categories and sub-categories were discussed above. To secure accuracy of analysis, the researcher performed three rounds of coding.

On a different note, the physical description of the two sets of corpus was generated and counted through the aid of three corpus linguistics tools: AntConc, WordCount, and UAM Corpus Tool useful computer applications in analyzing language features. The UAM Corpus Tool strives for large corpora in which rare linguistic features can be extracted, features such as parsing, mood, transitivity, theme and rheme, modality, and tagging that linguists scrutinize (O'Donnell, 2016). Conversely, WordCount is a web-based word, character, and syllable counter that gives a broad corpus description. It also includes readability, and keyword density (WordCounter, 2017). AntConc is for concordancing and analyzing texts (Anthony, 2014). Aside from this, AntConc gives concordance plot, file view, clusters, collocates, wordlist, and key wordlist. Through these softwares and online tool, specific adverbials of attitude and emphasis were efficiently located in, and their frequency count was easily generated. All three are manageable to use even without much training. They had helped the researcher in eliciting underlying components of the corpus that sometimes may not be seen by an analyst's naked eyes. Descriptive statistics, i.e. weighted average, was used to determine the frequency and percentages of the adverbials.

\section{FINDINGS AND DISCUSSION}

Before providing the key findings, it is valuable to 
Hernandez, A (forensic) stylistic analysis of adverbials of attitude and...

present first the physical description of the adverbials. In the interim, Table 1 gives the summary of the corpus' physical description by average number of tokens per sentence, total number of sentences, total number of tokens, and total number of adverbials.

Table 1. Physical description of Supreme Court decisions in PhE

\begin{tabular}{lrr}
\hline \multicolumn{1}{c}{ Physical Aspects } & \multicolumn{1}{c}{ RC } & \multicolumn{1}{c}{ RP } \\
\hline $\begin{array}{l}\text { Average number of tokens per sentence in a } \\
\text { corpus }\end{array}$ & 8.50 & 9.71 \\
\hline Average number of sentences per corpus & 315.48 & 368.11 \\
\hline Average number of tokens per corpus & $2,743.22$ & $3,620.70$ \\
\hline Total number of tokens & $74,067.00$ & $97,759.00$ \\
\hline Total number of adverbials & $1,623.00$ & $2,166.00$ \\
\hline
\end{tabular}

Note: Table 1 shows the physical description of the Supreme Court decisions in PhE.

As can be viewed, RP's corpus is lengthier as it contains 97, 759 tokens than RC's. Contrastingly, RP's sentences are more complex having 9.71 average number of tokens per sentence than RC's having 8.50. This finding is supported by the fact that the RP's average number of sentences is 368.11 which is higher than that of RC's 315.48. Legalese sentences, according to Tiersma (2000), can be chunked into smaller pieces without compromising the content; thus, Cruz and Pariña (2015) assert that complexity in legalese sentences may be superfluous. It can be deduced that 9.71 average number of tokens per sentence is digestible pieces comprising each sentence of the judgments against the average number of 18 words for sentences to be understandable as argued by Strunk and White (2000). Generally, RP's judgments somehow lack resemblance as evidenced by their scantly higher complexity across the physical aspects than that of RC's judgments. The complexity of RP's Supreme Court decisions is furthermore illustrated as they comprise 2, 166 adverbials which are relatively higher than RC's judgments that contain 1,623 only.

\section{Classes}

Unlike Quirk et al. (1985) and Dita (2011) who provided two categories of adverbs (i.e. evaluation to the subject of the clause, and judgment to the whole clause) of attitude, the current study discovered another that is evaluation to an action performed by the subject of the clause. Correctly (13 occurrences), importantly (10 occurrences), necessarily (15 occurrences), and personally (28 occurrences) are the most repetitive among the 22 adverbials. Both RC and RP's writing styles illustrate resemblance as the classifications of those four adverbials they use are similar, while they also pose variations in one way or another. Due to RP's higher number of adverbials of attitude (i.e. RP-36.97\% over RC-17.24\%; RP-20.17\% over RC-18.49\%; RP-26.72\% over RC-12.07\%), he may be assessed as a judge who is more attached to his writings disparate of RC. This is more revealed in his use of personally. When evaluating an action being performed by the subject of the clause, RP utilized the term 16 times that is four notches higher than RC's which is 12 times only. Two cases in point are

\section{CORONA-121211.txt}

Complainant alleged that respondent Diaz personally demanded money from him... (Evaluation to an action performed by the subject of the clause)

PUNO-093008.txt

The practice of soliciting cases for the purpose of gain, either personally or through paid... (Evaluation to the subject of the clause)

In addition, RP uses correctly frequently for judging the whole clauses and evaluating the action done by the subject of the clause, unlike RC. Instances are as follows.

\section{PUNO-050708.txt}

The Government cannot tolerate in its service a dishonest official, even if he performs his duties correctly and well,...

(Evaluation to an action performed by the subject of the clause)

\section{CORONA-082410.txt}

As correctly observed by Complainant, Respondents Acknowledgment is the best evidence that NO RESIDENCE CERTIFICATES...

(Judgment to the whole clause)

Quite similarly, RP utilizes importantly when both evaluating the action done by the subject of the clause, and giving judgment to the entire clause, whereas RP uses the adverb only when judging the whole clause. For example,

\section{PUNO-061208.txt}

More importantly, it is through the service of summons of the process server...

(Judgment to the whole clause)

CORONA-082410.txt

...document is also undisputed not only by [the] strength of Complainants documentary evidence but 
more importantly, by Respondents own judicial admission.

(Evaluation to the subject of the clause)

As for necessarily, RP often employs it when evaluating an action performed by the subject of the clause. He occasionally uses it when judging the whole clause. It is marked in his corpus since it is absent in the writings of RC across the three classes. This may be representing his distinctive authorship. Extracts are illustrated as follows.

\section{PUNO-021508.txt}

Necessarily, however, the freedom of television and radio broadcasting is somewhat lesser in scope than the freedom accorded to newspaper and print media. (Judgment to the whole clause)

PUNO-121605.txt

...the opportunity to cross-examine a witness but failed to avail himself of it, he necessarily forfeits the right to cross-examine...

(Evaluation to an action performed by the subject of the clause)

Conviction and doubt are the classes of adverbials of emphasis found in the texts. Adverbials of conviction (365 cases) outnumbered adverbials of doubt (79 cases). This can be explained by the legal tenet that justices have to establish authority and institute command in writing decisions; thus, skepticism against the case of the judgments is discouraged and expected of them. Notably, RP uses more adverbials of conviction than $\mathrm{RC}$ as the first occurred 214 times while the latter came about 151 times only. RP, then, demonstrates greater conviction than RC by using multiple adverbials of emphasis. Most recurrent conviction adverbials of emphasis are clearly (i.e. RP-7.40\% over RC-7.40\%), in fact (i.e. $\mathrm{RP}-7.67 \%$ over RC-3.84\%), indeed (i.e. RP-6.30\% over RC-4.66\%), merely (i.e. RP-6.58\% over RC$2.74 \%$ ), and fully (i.e. RP-5.48\% over RC-3.29\%). As $\mathrm{RP}$ uses more adverbials of conviction over RC, his samples are as follows.

\section{PUNO-101008.txt}

What [BBB] did and did not do afterwards clearly showed her impression.... (Conviction)

\section{PUNO-121605.txt}

...because I was already prepared to leave and have in fact told my relatives and friends... (Conviction) PUNO-121708.txt

If indeed she still needs to recuperate from her illness and go on extended sick leave, the matter... (Conviction)

PUNO-121708.txt

The Court fully agrees with the OCA Report and finds that the respondent failed... (Conviction)

\section{PUNO-012009.txt}

Verily, the bulk of cases pertaining to misrepresentation and falsification of... merely touches on the professional realm... (Conviction)

On the other hand, those that signify doubt are allegedly, apparently, presumably, likely, maybe, purportedly, and supposedly. Among these, allegedly is the most intermittent as it occurs 52 times far and beyond the other six. Likewise, it is unquestionably a legal term in forensic science as it is used habitually in the Supreme Court decisions in PhE. As can be seen, both RC (39 occurrences) and RP (40 occurrences) write using adverbials emphasizing doubt. While all of these adverbials can be synonymous in meaning and context, allegedly suggests that the two judges use it as the most legalistically appropriate adverbial of conviction among the seven as in the succeeding extracts.

\section{CORONA-020111.txt}

On 12 November 1999, Asst. Provincial Prosecutor Domingo C. Pineda allegedly issued a Manifestation... PUNO-121605.txt

Villas also referred to Commissioner Rodriguez the complaint of Lao who allegedly told him that he paid P60,000.00...

\section{Placements}

Strikingly, RP places adverbials of attitude in the middle of sentences, having $69.23 \%$ that is 81 occurrences - doubly higher than RC, having $34.19 \%$ that is 40 hits. In spite of this, RC's medial positioning of adverbials outnumbered his and RP's initial placement of adverbs. Thus, one dominant stylistic feature of RP and RC when writing Supreme Court decisions is their medial position of adverbials and that they less frequently place them in the initial position. However, RC's medial placement of these adverbials is more abundant. For the initial position, the most recurring ones are correctly, importantly, and necessarily. For the medial, personally, having 27 frequencies, is the most occurring style marker. Its remarkable frequency may be deduced from what McMenamin (2012) noted that judges may also transcend their subjective disposition into their writings of Court judgments. For example,

\section{PUNO-061208.txt}

After saving for his fare to Naga City, he personally served a copy of the summons to Ramirez on December 11, 2004.[9] (Medial)

\section{CORONA-121211.txt}

Complainant alleged that respondent Diaz personally demanded money from him to answer... (Medial)

On the other hand, correctly which was employed by RC and RP has 4 initial occurrences, 
Hernandez, A (forensic) stylistic analysis of adverbials of attitude and...

(3.42\%) from RP and 2 initial occurrences (1.71\%) from RC. Medially, RP used it 6 times (5.13\%) while RC had 1 occurrence or $0.85 \%$ only. For instance,

\section{PUNO-071408.txt}

As correctly pointed out by the City Prosecutors Office of Makati, it appears that the executive officers... (Initial)

PUNO-100608.txt

The Office of the Court Administrator has correctly noted that there are attendant mitigating... (Medial)

CORONA-020111.txt

As correctly pointed out by the complainant and the Investigating Justice, except for the abovementioned cases... (Initial)

CORONA-042412.txt

Consequently, Commissioner De Mesa and the IBP Board of Governors correctly recommended his disbarment... (Medial)

As regards the initial position of importantly, RP used it 5 times (4.27\%) while RP employed it just once $(0.85 \%)$. Medially, both authors used it twice $(1.71 \%)$. For instance,

\section{PUNO-121605.txt}

More importantly, it is well-settled that the essence of due process... (Initial)

\section{CORONA-022211b.txt}

...that a judge is the visible representation of the law, and more importantly of justice; he or she must, therefore, be the first... (Medial)

Initially and medially, necessarily transpired in RP's corpus only. Its 14 (11.97\%) medial occurrences are far more than its initial position of $1(0.85 \%)$ respectively. Hence, necessarily is another contrasting stylistic feature of RP which was not evident in the writings of RC. Here are the examples.

\section{PUNO-021508.txt}

Necessarily, however, the freedom of television and radio broadcasting is somewhat lesser... (Initial)

PUNO-061208.txt

The image of a court of justice is necessarily mirrored in the conduct, official... (Medial)

Comparatively, both adverbials of attitude and emphasis are remarkably visible in the medial position as RP and RC employ many of both adverbials in the middle of sentences.

Both initial and medial positions were observed in the judgments. Contrastingly, both judges very frequently place their adverbials of emphasis in the medial position. RP's adverbials in the medial have 201 or $46.96 \%$, while RC's have 150 or $35.05 \%$. Clearly, allegedly, indeed, in fact, merely, and fully are the most frequent ones. Clearly and allegedly. being the most frequent, have $64.15 \%$ equivalent to 54 occurrences. Both indeed and in fact are equally occurring as they have $51.81 \%$ (42 cases). This is succeeded by merely that has $41.94 \%$ (34 occurrences), then, fully that has $27.14 \% \quad$ (22 occurrences). Albeit differences of frequencies that can be seen on and between the judges, these are but little variations only. It can be inferred that both of their writing styles conform to the legal writing convention that judges should display certainty in their legal judgments so it would lead to no sign of qualm from Appellate court and other legal bodies (Ambwani, 2015). As both adverbials of attitude and emphasis appear right before the specific points, entities, or events they modify, the two Chief Justices attempt at revealing strong precision in their conviction and/or doubt on the facts they present and argue. In Supreme Court decisions, regular medial position of adverbials therefore signifies accuracy in writing. Below, the robustness of using these adverbs of emphasis is illustrated by the extracts with adverbs italicized. The points they modify are underlined.

\section{PUNO-121605.txt}

...so she could get a passport and a visa to work in Japan as a factory worker clearly showed that she was desperately in need of a job. CORONA-121211.txt

Under the circumstances, respondent is clearly guilty of grave misconduct which the Court...

Above, RP uses clearly to emphasize the verb showed and its direct object she was desperately in need of a job, while RC uses clearly to put more stress on the guilt of the subject. Below, RP employs allegedly to hint uncertainty towards the underlined ing gerundial phrase using petitioners name in dealing with some immigration officials and employees, whereas RC utilizes allegedly to emphasize verb phrase made to him.

\section{PUNO-121605.txt}

Private respondent was allegedly using petitioners name in dealing with some immigration officials and employees to expedite the...

\section{CORONA-011811b.txt}

Regardless of the representations allegedly made to him by Sy, Judge Dinopol should have immediately issued...

Regarding indeed and in fact below, RP accentuates the verb phrase be held liable, while RC highlights the noun phrase $a$ death threat. RP uses in fact to put emphasis on the verb issued and its direct object postdated checks.

\section{PUNO-093008.txt}

Respondent should indeed be held liable, for he was not just incompetent, he was practically useless... 
CORONA-041712.txt

However, it was established that there was indeed $a$ death threat against complainant and it...

PUNO-071408.txt

... as it had in fact issued, postdated checks covering the principal investments.

CORONA-011811b.txt

This conclusion, is in fact, bolstered by Judge Dinopols knowledge that the counsel for Metrobank...

Moreover, RP employs merely to refer to the verb phrase tends to diminish the faith of the people and that there is just one tendency, while RC uses it to emphasize the verb phrase gave the parties the opportunity. It is actually the action done by the subject.

\section{PUNO-050708.txt}

Any act or omission on their part which violates the norms of public accountability or even merely tends to diminish the faith of the people in the Judiciary...

CORONA-090611.txt

He explained that he merely gave the parties the opportunity to be heard and eventually dismissed the petition...

PUNO-022409.txt

She and her two sons were then fully supported by Jambrich.

CORONA-022211b.txt

We observe that in A.M. No. MTJ-01-1362, Judge

Limsiaco did not fully obey our directives.

Above, RP utilizes fully to modify supported, whereas RC uses it to determine obey. While medial placements of adverbs of attitude and emphasis are consistent and resembling in RP and RC, their frequencies are much distant from each other. It can be construed that both judges have unique stylistic variations.

\section{Environments}

While there are four environments of both adverbials: in split infinitive, with functor or function word, before conjunction, and within a noun phrase (Dita, 2011), the researcher however discovered three more categorized as beforelafter the verb, after an intensifier, and $n / a$ which refer to adverbials that are in the initial position evaluating the whole clause and appear before the subject of the sentence. $n / a$ has been used to avoid confusing it with the classes of adverbials of attitude and emphasis. RP and RC's adverbials are situated within particular environments with relatively high and low frequencies. Importantly, the ones that have greater frequencies have to be emphasized as they are suggestive of the recurrence of writing style. RP's with functor has the highest frequency, that is $26 \%$ of all the adverbials of attitude. RP's beforelafter the verb having $19.8 \%$ is second. Subsequent is RC's before/after the verb having $12.1 \%$ succeeded by RP's with functor that has 9.5\%. Thus, RP's environments of his adverbials of attitude particularly with functor, and RC's environments of his adverbials specifically beforelafter the verb can be said as their natural milieus. Supporting this, McMenamin (2012) reveals that authors reflect their unconscious manner of writing onto their written papers. Extracts are as follows.

\section{CORONA-022211.txt}

The practice of soliciting cases at law for the purpose of gain, either personally or through paid agents or brokers, constitutes malpractice. (Emphasis supplied.) (With functor/s)

\section{PUNO-050708.txt}

... a sheriff as an officer of the court upon whom the execution of a final judgment depends, $\underline{\text { must }}$ necessarily be circumspect and proper in his behavior. (With functor/s)

\section{CORONA-062910b.txt}

...the amount of P20, 000.00 from them, allegedly to be given to Judge Beltran, and that thereafter, she personally delivered to them... (Before/after a verb)

\section{PUNO-121605.txt}

...he necessarily forfeits the right to cross-examine and the testimony given on direct examination of the witness... (Before/after a verb)

The first two extracts exemplify with functor as personally and necessarily. They are surrounded by function words either and or, that are conjuncts, for personally, and must (modal) and be (copula) for necessarily. Conversely, the second two have verbs succeeded by personally and necessarily. Personally is placed before delivered, while necessarily is situated before forfeits.

As regards the environments of adverbials of emphasis, more adverbs of emphasis have greater number of frequencies. They are generally surrounded by all environments provided by Dita (2011). In detail, these are before/after the verb, after an intensifier, $n / a$ (that means the same as that for adverbials of attitude), before an infinitive phrase, before a prepositional phrase, and before a clause. More specifically, with functor, within a phrase/clause, before/after the verb, and $n / a$ have the paramount number of occurrences; they take in pairs simultaneously. With functor of RP (22.2\%) and RC $(17.86 \%)$ takes the highest frequency as it is the most recurrent of all the environments that have the most dominance. Within a noun phrase/clause ranks the second with RP having $14.8 \%$ and RC having $8.67 \%$. 
Before/after the verb notches the third spot, RP having $10.2 \%$ and RC having $7.65 \%$, and $n / a$ is the fourth, RC using $9.69 \%$ and RP $7.91 \%$. They come across allegedly, clearly, indeed, in fact, and merely which were used the most by the two drafters. These extracts illustrate them.

\section{CORONA-062910b.txt}

...Baccay that Pagulayan demanded and received money from him, allegedly to be given to Judge Beltran... (With functor/s)

PUNO-100608.txt

Barren is allegedly a liar and a falsifier who, in the past, had misappropriated the courts... (With functor/s)

CORONA-020111.txt

...was issued stating that a hearing was allegedly held wherein the plaintiff testified, the Psychological

Evaluation Report filed... (Within a clause)

PUNO-121605.txt

...the complaint of Lao who allegedly told him that he paid P60,000.00 to petitioner in exchange for a Chinese Visa and a passport for Taiwan. (Within a noun clause)

On the one hand, allegedly above is situated within two environments: within functors and within clauses. Him (pronoun) and to (preposition) surround allegedly in the first sentence, while is (linking verb) and $a$ (indefinite article) bracket the adverb. The second set of statements, on the other hand, contains underlined noun clauses, particularly adjectivals, where allegedly is placed within.

PUNO-020609.txt

These clearly show that complainants repurchased the property...

\section{CORONA-041712.txt}

The acts described in the complaint, the testimony of complainant and the witness, and the Executive

Judge's report clearly established that respondent... PUNO-012009.txt

...wherein she indicated that she was single although

in fact, she was already married...

CORONA-062910b.txt

In fact, the charge against her was investigated twice. PUNO-071608.txt

In fact, he was only occupying the subject lot by virtue of the permission granted him...

Clearly above is situated prior to the verbs show and established. As for in fact, the environment where it is categorized in the sentences above is $n / a$ as it is placed before the entire sentence.

CORONA-062910.txt

Indeed, it is clear now that there was really physical restraint...
PUNO-082008.txt

Indeed, petitioners purchase of the said land despite

the notice of lis pendens...

CORONA-011811b.txt

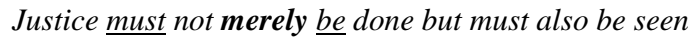
to be done.

\section{PUNO-071608.txt}

...executed on October 25, 1966, he, the late Felix

Ting Ho, was merely a possessor or occupant of the subject...

Finally, indeed and merely in the two sentences above have $n / a$ environment like the case of in fact. Merely, contrastingly, is with functors must (modal) and be (copula) for the first, while was (past tense linking verb) and $a$ (indefinite article) for the second. Not different from the case of the environments of adverbs of attitude, allegedly, clearly, indeed, in fact, and merely, of utmost repetition among the other adverbials of emphasis, are the relatively identifiable stylistic features of the two Filipino judges in terms of sentence environment.

\section{Implications to ELP}

After making an attempt of stylistically analyzing the two types of adverbials in Supreme Court decisions in $\mathrm{PhE}$ drafted by the two Chief Justices, this study anticipated that one may ask how do these stylistic aspects, i.e. classes, placements, and environments of adverbial expressions of attitude and emphasis implicate the pedagogical dimension of ELP? It is noteworthy to emphasize the pedagogical associations of these stylistic features toward (1) ELP professors or teachers, (2) law students and/or student lawyers, and (3) educated readers of Supreme Court decisions.

First, teachers of ELP may be provided with specific foci of teaching adverbials of attitude and emphasis in the ELP classroom. They could divide these foci into three as in classes, placements, and environments in that they can teach these aspects one at a time to their law students. Also, they may utilize the research interpretations and cited extracts given here as instances of authentic language for teaching forensic written discourse. As revealed by McMenamin (2012) and Finegan (2012), the two adverbials are not given much attention in forensic discourse. Therefore, it may be necessary now to teach these micro-syntactic items in the ELP classroom. As it is, law students and/or student lawyers may learn the stylistics of the two adverbials in Supreme Court decisions drafted in PhE. Learning them could increase their repertoire in practicing writing this legal document. Ambwani, (2015) once noted that judges who are given tasks that include writing Court opinions should learn the appropriate fashion of writing them. Studying the three aspects of the two adverbials may supplant such a gap among legal 
drafters of Court judgments. Furthermore, students could decide which among these would best suit the points or claims they need to assert and accentuate with respect to their conviction or doubt in practicing writing Supreme Court judgments. Thirdly, educated readers may be informed about the underlying stylistic explanations on their uses. It is univocally important that they should also have the knowledge about their classes, placements, and environments; thus, making sense of the linguistic behavior of the two adverbials in Supreme Court decisions.

\section{CONCLUSION}

To the best knowledge of the researcher's and his endeavor of searching for forensic linguistics studies in the Philippines, he has found a dearth of research especially on adverbials of attitude and emphasis in legal documents. Equally important is the fact that these two adverbials are given less attention in forensic linguistics (McMenamin, 2012; Finegan, 2012). More likely, forensic stylistics studies in the Philippines require resilient initiation to offer ELP teachers, law students, and/or student lawyers, and educated readers the writing style of justices in drafting court decisions. Therefore, this paper (forensically) stylistically analyzed the classes, placements, and environments of the two adverbials in Supreme Court decisions in $\mathrm{PhE}$ written by two Filipino Chief Justices.

Three classes were determined: evaluation to the subject of the clause, judgment to the whole clause, and evaluation to an action performed by the subject of the clause. Adverbials of attitude such as correctly, importantly, necessarily, and personally were the most frequent among the 22 adverbial expressions. RP's use of personally, being the most frequent in evaluating an action being performed by the subject of the clause, suggests his attachment when evaluating action and subject in Supreme Court decisions. Moreover, necessarily was marked in RP as it was absent in the writings of RC across the three classes. Thus, this entails RP's writing exhibits further certainty compared to the writing of RC. In contrast, adverbials of conviction outnumbered adverbials of doubt. RP demonstrates greater conviction than RC by using more multiple adverbials of emphasis. Most recurrent conviction adverbials of emphasis were clearly, in fact, indeed, merely, and fully, while the most frequent adverbial of doubt was allegedly. While most of the adverbials of doubt were utilized by the judges, allegedly, having the paramount occurrence simultaneous with their proximity of frequencies, suggests that the two judges use it as the most legalistically appropriate adverbial of doubt among the rest. Regarding placements, one prevailing stylistic feature of the two judges is that they placed both adverbials medially, and initially. Hence, both adverbials act right before the points they refer to which may be attributed to the justices' attempt at displaying exactitude in their conviction and/or doubt on the claims they present through their authorship. In the written discourse of Court decisions, therefore, the use of medial placement of adverbials indicates truthfulness in writing. While there are consistency and resemblance on the medial placement of adverbs of attitude between RP and RC, it can be inferred that both judges have unique stylistic variations since the frequencies of their respective medial positions are much distant from each other. They place their adverbials within particular adverbial environments with relatively high and low frequencies. In stylistic perspective, RP's attitudinal adverbial environments particularly with functor, and RC's beforelafter the verb can be said as their respective tendency of distinct authorships. Such environments are therefore suggestive of their varied writing styles.

While the findings are fairly sound and the interpretations understandable, some research trajectories could still be determined and further undertaken. One is that future studies may involve forensic discourse analysis in scrutinizing other linguistic dimensions of the discourse of Supreme Court judgments such as clauses, passives, and so on. Another is a different legal written discourse may be examined in terms of the adverbials explored in this study or other types of adverbs even, and contrast/compare its findings to the results of this paper. Doing this may pave way to revealing authorship variations in different written legal discourses. Univocally, a researcher may delve into utilizing more corpus linguistics tools in analyzing forensic texts. The researcher hopes that this study would provide a positive contribution to the field of forensic stylistics in the Philippines and that it may inspire applied linguists in exploring legal genres (forensically) stylistically. As forensic linguistics is an emerging field in the Philippines, there are more to be investigated today and in the future.

\section{ACKNOWLEDGEMENT}

The researcher would like to thank the Lord Almighty, for His wisdom and guidance in writing this paper, and his family, for their love, support, and inspiration. $\mathrm{He}$ is also grateful to the anonymous reviewers for their valuable suggestions.

\section{REFERENCES}

Alabi, V. A. (2011). Stylistic features of the legal discourse. Retrieved from 
Hernandez, A (forensic) stylistic analysis of adverbials of attitude and...

https://www.ajol.info/index.php/ujah/article/view $/ 102581$.

Ambwani, S. (2015). The art of writing judgment. Retrieved from http://www.ijtr.nic.in/webjournal/3.htm.

Anthony, L. (2014). AntConc (Version 3.4.3) [Computer Software]. Tokyo, Japan: Waseda University. Available from http://www.laurenceanthony.net/.

Bautista, M. L. S. (2000). Defining standard of Philippine English: Its status and grammatical features. Manila: De La Salle University Press.

Bernardo, A. S. (2013). English(es) in college English textbooks in the Philippines. US-China Foreign Language, 11(5), 355-380.

Cruz, S. \& Pariña J. C. M. (2015). Legal English in court resolutions: A stylistic analysis. Presented at the DLSU Research Congress 2015, De La Salle University, Manila. De La Salle University.

Dita, S. N. (2011). The grammar and semantics of adverbial disjuncts in Philippine English. In M. L. S. Bautista (Ed.), Studies on Philippine English: Exploring the Philippine component of the International Corpus of English (pp. 33-50). Manila, the Philippines: Anvil Publishing, Inc. for De La Salle University.

Feng, Z. (2012). On the stylistics features of Legal English. World Journal of English Language, (2) 2, 29-35.

Finegan, E. (2012). Corpus linguistic approaches to 'legal language': Adverbial expression of attitude and emphasis in Supreme Court opinions. In M. Coulthard \& A. Johnson (Eds.), The Routledge Handbook of Forensic Linguistics (pp. 65-76). New York, NY: Routledge.

Gustilo, L. E. (2010). "Although if is more frequent than whether ...": An analysis of the uses of adverbial clauses in Philippine English research articles. Philippines ESL Journal, 4, 24-44.

Gustilo, L. E. (2011). Modal auxiliaries in Philippine English newspapers: A corpus-based analysis. Philippine ESL Journal, 6, 81-109.

Hernandez, H. P. (2017). Tagalog and Philippine English online newspaper headlines: A contrastive study. Presented at 2017 Linguistic Society of the Philippines - National Conference and General Meeting, Far Eastern University, Manila.

Khan, R. B., \& Khan, S. Q. (2015). Stylistics Study of Legal language. International Journal of Engineering Research and General Science, 3(1), 631-647.
Krivchikova, N. L., Koteneva, I. A., Sedykh, A. P., \& Trescheva, N. V. (2015). Stylistic characteristics of a legislative text. Retrieved from http://dspace.bsu.edu.ru/bitstream/123456789/14 362/1/Krivchikova_Stylistic_15.pdf.

Lisina, N. (2013). Stylistic features of legal discourse. (Unpublished master's thesis). University of Oslo, Blindern, Oslo.

Llamzon, T. A. (1969). Standard Filipino English. Manila: Ateneo University Press.

Martin, I. P. (2014). English language teaching in the Philippines. World Englishes, 33(4), 472-485.

McMenamin, G. R. (2012). Theory and practice of forensic stylistics. In M. Coulthard \& A. Johnson (Eds.), The Routledge Handbook of Forensic Linguistics (pp. 487-507). New York: Routledge.

Nawaz, N., Bilal, H. A., \& Khan, T. (2013). Language of law: Stylistic analysis of a legal document. International Journal of Research in Management, 3(2), 221-243. Retrieved from http://www.rspublication.com/ijrm/ijrm_index.ht $\mathrm{m}$.

O’Donnell, M. (2016). UAM corpus tool (Version 3.3f). Retrieved from http://www.corpustool.com/index.html.

Peña, P. S. (1997). Philippine English in the classroom. In M. Bautista (Ed.), English is an Asian language: The Philippine context (pp. 87102). Australia: The Macquarie Library Pty.

Quirk, R., Greenbaum, S., Leech, G., \& Svartvik, J. (1985). A comprehensive grammar of the English language. London, the United Kingdom, \& New York, NY: Longman Group Limited.

Simpson, P. (2004). Stylistics: A resource book for students. New York: Routledge.

Strunk, W., \& White, E. B. (2000). The elements of style $\left(4^{\text {th }} e d\right.$.). Canada: Allyn \& Bacon.

Tiersma, P. M. (2000). Legal language. University of Chicago Press, Chicago.

WordCounter. (2017). What is WordCounter? Retrieved from https://wordcounter.net/.

Yumul-Florendo, M. R. (2012). Initial study of emerging features of academic Philippine English among freshmen in the University of the Philippines Baguio. Educational Research, 3(7), 566-571. Retrieved from http://www.interesjournals.org/ER.

Zhu, J., \& Wu, Q. (2011). A brief analysis on the stylistic features of English for business contracts. Theory and Practice in Language Studies, 1(12), 1849-1852. 